\title{
Metabolism of Deoxynivalenol, a Trichothecene Mycotoxin, in Sweet Potato Root Tissues
}

\author{
(Received February 15, 1990) \\ Masayuki Fujita and Takumi Yoshizawa \\ (Faculty of Agriculture, Kagawa University: Miki-cho, Kita-gun, Kagawa, Japan)
}

\begin{abstract}
Sweet potato root tissues were used as an experimental model system for metabolism of trichothecenes in plants. ${ }^{14} \mathrm{C}$-Labeled deoxynivalenol was rapidly metabolized in the root tissues, most of the administered deoxynivalenol having disappeared by day 2. The half-life of the toxin in the root tissues was estimated to be less than $5 \mathrm{hr}$. By reverse-phase HPLC and TLC, it was demonstrated that the toxin was converted to at least three metabolites in the root tissues. The relationships between the parent toxin and the three metabolites are discussed on the basis of the time course of the metabolic transformation of the toxin in the root tissues.
\end{abstract}

Key words: deoxynivalenol; trichothecene; mycotoxin; Fusarium; sweet potato

\section{Introduction}

Deoxynivalenol is a well-known trichothecene mycotoxin produced by several species of $\mathrm{Fu}$ sarium. The toxin has been found together with nivalenol and zearalenone not only in a number of cereals including wheat, berley and corn, but also in commercial foods in many countries ${ }^{1)}$. Cereals contaminated with deoxynivalenol are associated with feed refusal, vomiting and diarrhea in farm animals ${ }^{2}$. Moreover, the toxin has been involved etiologically in food-borne human intoxications ${ }^{3)}$. Thus, the worldwide occurrence of the mycotoxin in major agricultural commodities is of concern from the viewpoint of potential risk to human and animal health.

In general, the toxigenic Fusarium species invade cereal plants during cultivation in fields, resulting in the contamination of cereal grains with the trichothecene mycotoxins before harvest. Although it is anticipated that there are some interactions between trichothecenes produced in crop fields and host plants, very limited studies have been done on the fate of trichothecenes in plants before harvest and during storage. Jarvis et $\mathrm{l}^{4}$ indicated that seedlings of Brazilian shrub, Baccharis megapotamica, fed with macrocyclic trichothecenes, roridin $A$ and verrucarin $\mathrm{A}$, metabolized them in high yields to their corresponding $8 \beta$-hydroxyl derivatives. Miller and Arnison ${ }^{5)}$ found that deoxynivalenol was converted to three compounds in suspension cultures of the Fusarium head blightresistant wheat cultivar, Frontana. Fujita and Yoshizawa ${ }^{6,7)}$ showed that trichothecene mycotoxins and ochratoxin $\mathrm{A}$ induced many kinds of phytoalexins such as ipomeamaronol and ipomeamarone in sweet potato root tissues in vivo and that, at the same time, individual mycotoxins were metabolized to unidentified derivatives in the plant tissue. Further studies including characterization and identification of metabolites could provide significant new knowledge for the evaluation of food and feed safety.

This paper presents evidence that deoxynivalenol is rapidly converted to at least three metabolites in sweet potato root tissues, used as an experimental model system.

\section{Materials and Methods}

\section{Plant material}

Sweet potato (Ipomoea batatas, Kokei No. 14) roots were purchased from a local market. The parenchymatous tissue of sweet potato roots was cut into discs $(16 \mathrm{~mm}$ in diameter and $c a .3$ $\mathrm{mm}$ thick) according to the procedures described previously ${ }^{6), 7)}$ and used for in vivo metabolism 
studies.

\section{Preparation of $\left[{ }^{14} \mathrm{C}\right]$ deoxynivalenol}

Radiolabeled toxins were prepared biosynthetically by feeding ${ }^{14} \mathrm{C}$-labeled acetate to a deoxynivalenol-producing strain of Fusarium graminearum 1352. The fungus was cultured in $100 \mathrm{ml}$ of yeast extract-polypeptone-sucrose medium with reciprocal shaking at $28^{\circ} \mathrm{C}$ for 2 days, during which time $\left[1-{ }^{14} \mathrm{C}\right]$ acetic acid sodium salt $(1.89 \mathrm{GBq} / \mathrm{mmol}, 20 \mathrm{MBq}$ dissolved in $1 \mathrm{ml}$ of sterile water, Centre Détudes Nucléaires de Saclay, France) was added followed by incubation for an additional 3 days. The culture filtrate was applied to a column $(2 \mathrm{~cm}$ i. d. $\times 9 \mathrm{~cm}$ long) of Amberlite XAD-2 resin (Rohm \& Haas Co., Philadelphia, PA) and adsorbents on the resin were eluted with acetone. The radioactive fraction was chromatographed successively on the following columns: Florisil, silica gel and Sep-Pak C18 (Water Associates, Inc., Milford, MA). By these procedures, $\left[{ }^{14} \mathrm{C}\right]$ deoxynivalenol (7.48 MBq/mmol, radiochemical purity of over $97 \%)$ and $\left[{ }^{14} \mathrm{C}\right] 3$-acetyldeoxynivalenol $(7.26 \mathrm{MBq} /$ mmol, radiochemical purity of over $98 \%$ ) were obtained with an incorporation rate of $7.2 \%$. Detailed procedures will be published elsewhere. The labeled deoxynivalenol was dissolved in water for administration to the sweet potato root tissues. The final concentration of this solution was $0.475 \mathrm{mg} / \mathrm{ml}(1.60 \mathrm{mM})$ and 12 $\mathrm{kBq} / \mathrm{ml}$.

\section{Administration of $\left[{ }^{14} \mathrm{C}\right]$ deoxynivalenol to sweet potato root tissues}

The discs were preincubated at $30^{\circ} \mathrm{C}$ for 1 day on a stainless steel net in a plastic box under moist conditions. The surface of each disc was treated with $50 \mu 1$ of $1.60 \mathrm{mM}\left[{ }^{14} \mathrm{C}\right]$ deoxynivale$\mathrm{nol}(c a .600 \mathrm{~Bq} / \mathrm{disc})$ and incubated again for 0 , 1,2 or 4 days in the same way, except for putting a Petri dish containing $20 \%(\mathrm{w} / \mathrm{v})$ aqueous $\mathrm{KOH}$ solution in the plastic box. Five discs were prepared for each incubation time.

Extraction of metabolites from sweet potato root tissues

Five discs were collected at each time period and homogenized with $25 \mathrm{ml}$ of acetonitrilewater $(3: 1, \mathrm{v} / \mathrm{v})$. The homogenate was centrif- uged at $3,000 \mathrm{rpm}$ for $10 \mathrm{~min}$. The precipitate was extracted twice with $25 \mathrm{ml}$ of acetonitril-water $(3: 1, v / v)$. The combined supernatant solution was evaporated to dryness under reduced pressure. The residue was rinsed successively with $5 \mathrm{ml}, 2 \mathrm{ml}, 2 \mathrm{ml}$ and $1 \mathrm{ml}$ of methanol to remove insoluble material. The combined methanol solution was evaporated to dryness under reduced pressure. The resulting residue was dissolved in $2 \mathrm{ml}$ of methanol-water $(3: 1$, $\mathrm{v} / \mathrm{v}$ ) and was subjected to TLC and HPLC analyses.

\section{TLC analysis}

The extract of sweet potato root tissues incubated with ${ }^{14} \mathrm{C}$-labeled deoxynivalenol was applied on a TLC plate (Silica gel $70 \mathrm{~F}_{254}$ Platewako, Wako Pure Chemical Industries, Osaka, Japan). The plate was developed three times to a height of $2 \mathrm{~cm}$ from the origin with methanol followed by developing twice with chloroformmethanol $(5: 1, \mathrm{v} / \mathrm{v})$ to a $15 \mathrm{~cm}$ height. After development, the portions of the chromatogram bearing the deoxynivalenol fraction ( $R f$ 0.73$0.87)$ were scraped from the plate. The scraped silica gel was collected into a scintillation vial (20 ml vol.) with $0.4 \mathrm{ml}$ of ethanol and $0.2 \mathrm{ml}$ of water.

\section{HPLC analysis}

HPLC was performed with a Shimadzu LC-6A liquid chromatograph fitted with a Shimadzu SPD-6A UV detector and a Shimadzu SCL-6A system controller. The $6 \times 150 \mathrm{~mm}$ column packed with Shim-pak CLC-ODS $(5 \mu \mathrm{m})$ was eluted with a gradient of $10-100 \%(\mathrm{v} / \mathrm{v})$ methanol in water at a flow rate of $1 \mathrm{ml} / \mathrm{min}$. Fractions of the eluate $(0.5 \mathrm{ml})$ were collected in scintillation vials ( $10 \mathrm{ml}$ vol.).

\section{Assay of radioactivity}

The radioactive samples collected into vials were mixed with $10 \mathrm{ml}$ (in TLC analysis) or $5 \mathrm{ml}$ (in HPLC analysis) of scintillation solution (Cle-ar-sol I, Nacalai Tesque, Osaka, Japan), and the radioactivity was measured with an Aloka LSC100 liquid scintillation counter.

\section{Results and Discussion}

Recoveries of the administered ${ }^{14} \mathrm{C}$-radio- 
Table 1. Variation of Amount of ${ }^{14} \mathrm{C}$-Labeled Deoxynivalenol in Sweet Potato Root Tissues during Incubation

\begin{tabular}{ccc}
\hline $\begin{array}{c}\text { Incubation } \\
\text { time } \\
\text { (day) }\end{array}$ & $\begin{array}{c}\text { Radioactivity } \\
\text { (dpm) }\end{array}$ & $\begin{array}{c}\text { Relative } \\
\text { radioactivity } \\
(\%)\end{array}$ \\
\hline 0 & 2,507 & 100 \\
1 & 198 & 7.9 \\
2 & 41 & 1.6 \\
4 & 16 & 0.8 \\
\hline
\end{tabular}

a Relative radioactivity was expressed as a percentage of the radioactivity of deoxynivalenol recovered at day 0 .

activity from sweet potato root tissues slightly decreased with incubation time, i.e. $95 \%$ at day 0 and $87 \%$ at day 4 . A small amount $(7 \%)$ of the radioactivity was found in the methanolinsoluble material after incubation for 4 days. No degradation of the toxin into $\mathrm{CO}_{2}$ was observed, since an insignificant amount of ${ }^{14} \mathrm{CO}_{2}$ was trapped with $20 \%$ aqueous $\mathrm{KOH}$ solution during incubation.

In order to clarify the biodegradation of deoxynivalenol in sweet potato root tissues, the remaining ${ }^{14} \mathrm{C}$-labeled deoxynivalenol after incubation was measured by TLC (Table 1). Most of the radioactivity in the deoxynivalenol region ( $R f, c a$. 0.8) had disappeared by day 2 . The half-life of the toxin in the root tissues seemed to be less than $5 \mathrm{hr}$. TLC was insufficient to resolve individual metabolites as the radioactivity was broadly located in the low- $R f$ region (the origin to $R f, c a$. 0.5).

The extract of sweet potato root tissues incubated for 4 days with ${ }^{14} \mathrm{C}$-labeled deoxynivalenol was analyzed by reverse-phase HPLC. As shown in Fig. 1, three radioactive peaks, tentatively referred to as compounds $\mathrm{A}, \mathrm{B}$ and $\mathrm{C}$, were found on the radiochromatogram. Compound $A$ was eluted more quickly $\left(t_{\mathrm{R}}, c a .10 \mathrm{~min}\right)$ from the reverse-phase column than deoxynivalenol $\left(t_{R}\right.$, ca. $13.5 \mathrm{~min}$ ), whereas compound $\mathrm{C}$ was eluted more slowly $\left(t_{\mathrm{R}}, c a .19 \mathrm{~min}\right)$. Compound $\mathrm{B}$ had a retention time corresponding to that of deoxynivalenol. However, on the basis of the data at day 4 shown in Table 1, it was suggested that compound $\mathrm{B}$ found in the day 4 extract was not deoxynivalenol but its unknown metabolite,

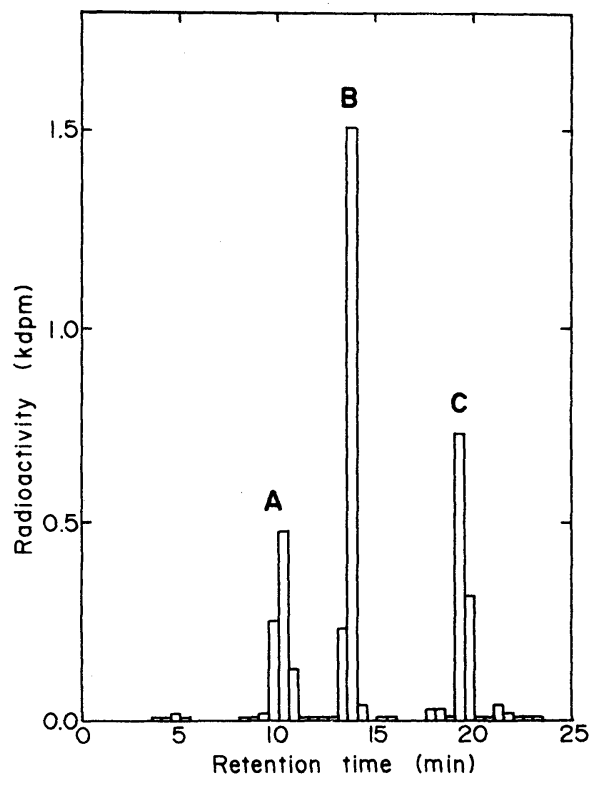

Fig. 1. HPLC of the extract of sweet potato root tissues incubated for 4 days with $\left[{ }^{14} \mathrm{C}\right] \mathrm{de}$ oxynivalenol

Peaks from left to right are referred to as compounds A, B and C. The peak of compound $B$ at 13.5 min corresponds to that of $\left[{ }^{14} \mathrm{C}\right]$ deoxynivalenol.

compound $\mathrm{X}$. Neither compound $\mathrm{A}$ nor $\mathrm{C}$ was detected at day 0 , indicating that they were not artifacts produced during extraction but metabolites produced by enzymes in the plant tissues. In the previous study ${ }^{7}$, sweet potato root tissues were treated with unlabeled deoxynivalenol for 1 day in the same manner as described in this paper. The tissue extract gave a blue spot due to a compound other than the substrate on a TLC plate after treatment with 4 -( $p$-nitrobenzyl)pyridine and tetraethylenepentamine ${ }^{8}$, suggesting that deoxynivalenol metabolite(s) could have retained the original epoxide ring. However, it is not clear which compound among the three found in reverse-phase HPLC corresponds to this metabolite.

Compound $\mathrm{C}$ seemed to be more hydrophobic than deoxynivalenol, considering its behavior on reverse-phase HPLC. Chakrabarti and Ghosal $^{9)}$ reported the presence of fatty acid esters of trichothecene mycotoxins such as trichothecolone, scirpenetriol and T-2 tetraol in the fruit of banana infected with $F$. moniliforme 


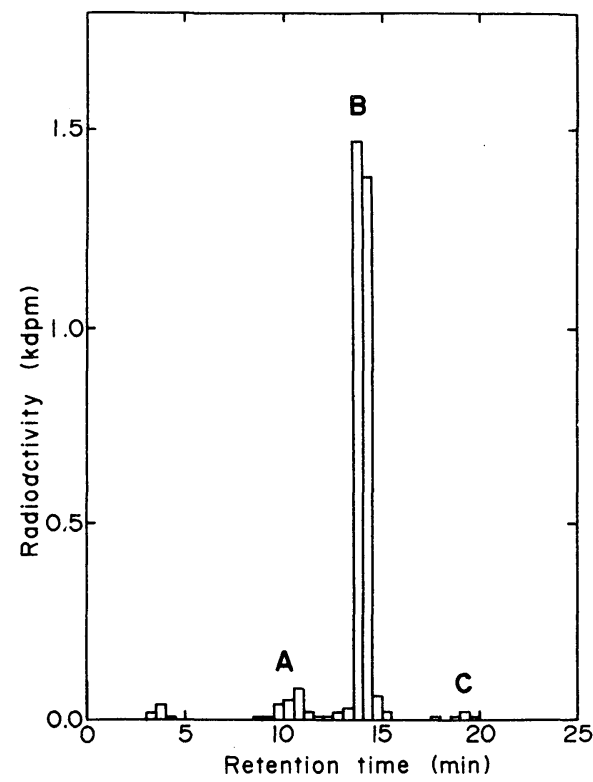

Fig. 2. HPLC of the alkali-treated extract of sweet potato root tissues incubated for 4 days with $\left[{ }^{14} \mathrm{C}\right]$ deoxynivalenol

The extract of day 4 was allowed to stand in methanol-water $(2: 1, \mathrm{v} / \mathrm{v})$ containing $0.18 M \mathrm{NaOH}$ for $3 \mathrm{hr}$ at room temperature.

Sheldon in the field and in storage. In order to clarify the chemical properties of compound $\mathrm{C}$, an aliquot of the extract of the discs incubated for 4 days was allowed to stand in methanolwater $(2: 1, \mathrm{v} / \mathrm{v})$ containing $0.18 M \mathrm{NaOH}$ for 3 $\mathrm{hr}$ at room temperature and then subjected to HPLC analysis. Interestingly, as shown in Fig. 2, not only compound $\mathrm{C}$ but also compound $\mathrm{A}$ almost disappeared after the alkaline treatment to give a single peak with a retention time similar to that of compound $\mathrm{B}$ on the radiochromatogram. This substance(s) $(R f$, less than $0.5)$ was clearly distinguished from deoxynivalenol $(R f, c a .0 .8)$ by TLC analysis. Therefore, it is possible that compounds $\mathrm{A}$ and $\mathrm{C}$ might correspond to conjugates of compound $\mathrm{X}$, which was released by the alkaline treatment.

Young and Miller ${ }^{10)}$ suggested the presence of deoxynivalenol glycoside from translocation studies of deoxynivalenol in corn. Furthermore, Miller and Arnison ${ }^{5}$ found three metabolites of deoxynivalenol in suspension cultures of the wheat cultivar, Frontana, which is resistant to fusarium head-blight. Retention times of these

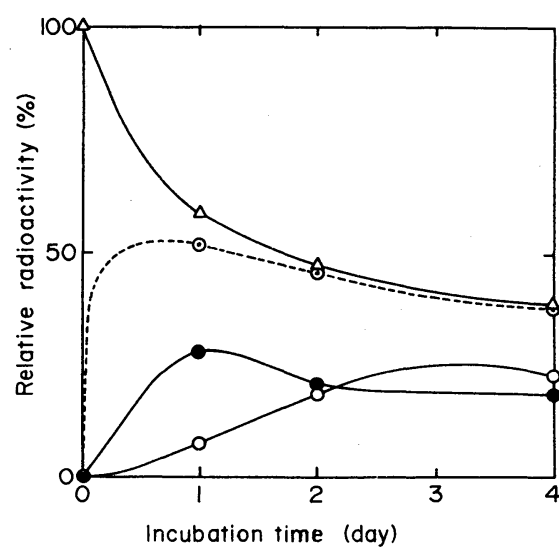

Fig. 3. Time course of the metabolic transformation of $\left[{ }^{14} \mathrm{C}\right]$ deoxynivalenol in sweet potato root tissues

$\triangle$ : compound B (deoxynivalenol plus compound X) estimated by HPLC; 9 : compound A; $\bigcirc$ : compound $\mathrm{C}$; $\odot$ : compound $\mathrm{X}$ Amount of compound $\mathrm{X}$ was estimated by subtracting the amount of deoxynivalenol measured by TLC (Table 1) from the amount of compound B calculated by HPLC. The relative radioactivity was expressed as a percentage of the total radioactivity recovered at day 0 .

metabolites were less than that of deoxynivalenol in reverse-phase HPLC. The authors indicated that one of them was compatible with a glycoside though others were breakdown products with smaller molecular weights than that of deoxynivalenol. On the other hand, our preliminary study showed that 15-glucosyldeoxynivalenol had a retention time similar to that of deoxynivalenol in reverse-phase HPLC but it had a smaller $R f$ value than deoxynivalenol in TLC on silica gel (data not shown). Thus, we can not rule out the posibility that compound $\mathrm{X}$ is a glycoside derivative of deoxynivalenol. However, neither of the transformation products of compound A nor compound C could be a glycoside derivative of compound $\mathrm{X}$ since the alkaline treatment adopted in this study was too weak to cleave a glycoside linkage.

The time course of the apparent metabolic transformation of deoxynivalenol in sweet potato root tissues is shown in Fig. 3. The amount of compound $\mathrm{X}$ was estimated by subtracting the amount of deoxynivalenol measured 
by TLC analysis (Table 1.) from the amount of compound B (mixture of deoxynivalenol and compound $\mathrm{X}$ ) calculated by HPLC analysis. Compound $\mathrm{X}$ seemed to appear soon after administration, and then increased remarkably for several hours accompanied by a drastic decrease of the substrate. The accumulation of compound $\mathrm{X}$ reached a maximum $(53 \%)$ and then declined slowly within one day. Compound A emerged after administration, increased until $c a$. day 1 (maximum value, $28 \%$ ), and then declined slowly. Compound $\mathrm{C}$ appeared with a lag time of several hours and increased slowly for around 3 days (maximum value, 25\%). The ratios of compound $\mathrm{A}$ to compound $\mathrm{X}$ at day 1 and day 4 were 3.6 and 0.83 , respectively. These results suggest that the substrate was initially metabolized to compound $\mathrm{X}$, which was then converted to compound $\mathrm{A}$ and finally to compound C.

In this study, sweet potato root tissues, which have a high metabolic activity towards deoxynivalenol, were used as an experimental model system for metabolism of trichothecenes in plants. In the same plant model system, $\left[{ }^{14} \mathrm{C}\right]$ nivalenol was metabolized to afford three derivatives (to be published elsewhere). Furthermore, we are investigating the metabolism of various kinds of mycotoxins in diverse plant model systems (potato, taro, carrot, etc.). The results suggest that the amounts of toxins estimated to be present in crops might be very different from those present in practice. Further studies, including identification of metabolites, could provide significant new knowledge for the evaluation of food and feed safety.

\section{Acknowledgments}

The authors wish to thank Drs. J. D. Miller and M. Savard, Plant Research Centre, Agriculture Canada, Ottawa, for their kind supply of 15glucosyldeoxynivalenol and useful suggestions for revision of the manuscript.

\section{References}

1) Jelinek, C. J., Pohland, A.E., Wood, G.E.: J. Assoc. Off. Anal. Chem. 72, 223-230 (1989).

2) Bhat, R. V., Beedu, S. R., Ramakrishna, Y., Munshi, K. L.: Lancet, Jan. 7, 35-37 (1989).

3) Ueno, Y. ed: "Trichothecenes-Chemical, Biological and Toxicological Aspects" (1986), Elsevier, Amsterdam.

4) Jarvis, B. B., Midiwo, J. O., Tuthill, D.: Science 214, 460-462 (1981).

5) Miller, J. D., Arnison, P. G.: Can. J. Plant Pathol. 8, 147-150 (1986).

6) Fujita, M., Yoshizawa, T.: Proc. Jpn. Assoc. Mycotoxicol. 25, 29-30 (1987).

7) Fujita, M., Yoshizawa, T.: J. Food Hyg. Soc. Japan 30, 501-505 (1989).

8) Takitani, S., Asabe, Y., Kato, T., Suzuki, M., Ueno, Y.: J. Chromatogr. 172 355-342 (1979).

9) Chakrabarti, D. K., Ghosal, S.: Appl. Environ. Microbiol. 51, 217-219 (1986).

10) Young, J. C., Miller, J. D.: Can. J. Plant Sci. 65, 4753 (1985). 